\title{
Medievalista
}

\section{Hilário Franco Júnior, Cocagne: Histoire d'un pays imaginaire}

Isabel Barros Dias

\section{OpenEdition}

\section{Journals}

\section{Edição electrónica}

URL: https://journals.openedition.org/medievalista/1545

DOI: 10.4000/medievalista. 1545

ISSN: 1646-740X

\section{Editora}

Instituto de Estudos Medievais - FCSH-UNL

\section{Refêrencia eletrónica}

Isabel Barros Dias, «Hilário Franco Júnior, Cocagne: Histoire d'un pays imaginaire», Medievalista [Online], 17 | 2015, posto online no dia 01 junho 2015, consultado o 21 setembro 2021. URL: http:// journals.openedition.org/medievalista/1545 ; DOI: https://doi.org/10.4000/medievalista.1545

Mediavalista está licenciado com uma Licença Creative Commons - Atribuição-NãoComercial 4.0 Internacional. 
Título: Recensão: FRANCO JÚNIOR, Hilário - Cocagne: Histoire d'un pays imaginaire. Préface de Jacques Le Goff. Paris: Les éditions Arkhê, 2013, 380 pp. [ISBN: 978-2-918682-2-19].

Autor: Isabel Barros Dias

Universidade: Universidade Aberta - Departamento de Humanidades

Faculdade e Departamento / Unidade de Investigação: IELT-EISI / IEM (FCSH-UNL)

Código Postal: 1269-001 Lisboa

Cidade: Lisboa

País: Portugal

Contacto: isabel.dias@uab.pt

Fonte: Medievalista [Em linha]. Direc. José Mattoso. Lisboa: IEM.

Disponível em: http://www2.fcsh.unl.pt/iem/medievalista/

ISSN: 1646-740X

Data do texto: Setembro de 2014 


\section{Recensão}

\section{FRANCO JÚNIOR, Hilário - Cocagne: Histoire d'un pays imaginaire. Préface de Jacques Le Goff. Paris: Les éditions Arkhê, 2013, 380 pp. [ISBN: 978-2-918682-2-19]}

\section{Isabel Barros Dias}

Cocagne: Histoire d'un pays imaginaire consiste na reedição do livro de Hilário Franco Júnior Cocanha. A história de um país imaginário, inicialmente publicado em São Paulo, em 1998, e que agora reaparece em versão traduzida para o francês e revista pelo autor.

O autor inscreve o seu trabalho na "história social do imaginário" (p. 14), convocando para o seu desenvolvimento três grandes áreas disciplinares: o imaginário, a literatura e a história, socorrendo-se ainda, pontualmente, da análise lexical e da etimologia, bem como de conceitos da sociologia e da psicologia. O estudo parte de um texto literário produzido no Norte da França, em meados do século XIII, o Fabliau de Cocagne, para identificar ideias e sentimentos que são seguidamente articulados com o contexto social e histórico coevo. O imaginário não é aqui entendido ao nível da imaginação individual, nem como a soma destas imaginações, mas sim como uma estrutura complexa onde se integram mitos, ideologias e utopias (p. 16). Assume-se igualmente que o imaginário integra os traços distintivos de cada sociedade, sendo por isso uma via privilegiada para o entendimento dessa mesma realidade.

Apesar de refletir os anseios e as necessidades profundas de um dado grupo num determinado momento histórico, o Fabliau de Cocagne constituiu igualmente um fenómeno de longa duração. Por um lado, considera-se que terá reunido traços essenciais reportáveis a meados do século anterior e, pelo outro lado, verifica-se que o 
tema perdurou, por vezes com outras designações, mas mantendo o mesmo sentido, até aos séculos XVIII-XIX, tendo ainda sido identificado um folheto de cordel de meados do século XX que também aborda o tema da Cocanha. A estrutura do livro espelha esta realidade: a sua maior parte é dedicada a uma profunda análise temática do fabliau francês que despoletou o assunto (cap. I a V) sem, no entanto, descurar a existência de ecos e de sequelas, apresentados e comentados nos dois últimos capítulos (VI e VII).

O estudo do Fabliau de Cocagne começa pela identificação de múltiplas semelhanças com textos e tradições anteriores (orientais, clássicas, bíblicas, celtas, escandinavas, muçulmanas e cristãs medievais) e pela diversidade da sua consideração pela crítica precedente (paródia, utopia, mito, representação do topos do mundo às avessas, expressão folclórica...), passando o autor seguidamente à consideração de quatro grandes temas, apresentados como estruturantes desta “utopia de evasão” (p. 21) que concretiza e dá resposta a fantasmas alimentares, sexuais e sociais: a abundância, a ociosidade, a juventude e a liberdade.

A ideia da Cocanha como terra da abundância será uma resposta à ameaça real e permanente da fome, bem como à imposição de dias de jejum e de abstinência, à condenação do pecado da gula por oposição ao louvor do ascetismo, e ainda à penúria de bens como roupa e calçado. Estas necessidades terão estimulado sonhos de abundância onde o instinto primordial da vontade de comer é satisfeito em abundância, gratuitamente, para todos e de modo luxuoso.

Contrariando o prestígio crescente do trabalho, assente em valores burgueses e eclesiásticos, a Cocanha apresenta-se como o local onde a ociosidade é recompensada, assumindo-se aqui a perspetiva aristocrática do desprezo pelo trabalho e ideias de algumas correntes de pensamento da época. O autor salienta ainda o ultrapassar das condicionantes espacio-temporais: a Cocanha surge como um não espaço ao qual não se sabe como chegar (na linha da tradição das viagens iniciáticas, para o Além ou para Outros Mundos) e, além disso, o facto dos excessos e das festas serem contínuas, rompe a noção de tempo marcada pela sucessão de dias de trabalho e festivos. O dinheiro torna-se inútil porque tudo é grátis e a usura perde sentido, também porque o tempo deixa de existir nos moldes tradicionais.

Cocanha é ainda o local onde se realiza o sonho da juventude eterna e onde se vive em liberdade. O autor sublinha aqui o valor do riso como elemento rejuvenescedor, além de 
libertador enquanto forma de lidar com angústias, medos, tabus e sentimentos mais constrangedores ou perturbadores e, nesta linha, estabelece algumas comparações com festas carnavalescas, dando especial atenção aos charivaris. Enquanto terra de liberdade, Cocanha apresenta-se como uma resposta à organização da sociedade medieval. Os poderes instituídos são desafiados pela proposta de uma sociedade na qual traços anarquistas podem ser vislumbrados: não existe estado, nem dinheiro, nem repressões e vive-se em total liberdade, prazer, concórdia e felicidade. No que se refere à liberdade sexual, entre os modelos cristão (moral) e o cortês (adúltero, anti-cristão), Cocanha propõe uma terceira via, a da liberdade sexual e da escolha livre de parceiros. A orgia que se concretiza numa vida dedicada a comer, beber e fazer amor configura-se assim como alternativa à organização social e à moral cristãs. A importância dada à liberdade permite ainda a aproximação do fabliau à poesia dos goliardos, sendo aqui sublinhado o papel sociopsicológico e de divertimento de alguma poesia que permite ultrapassar os problemas da realidade objetiva.

A articulação entre a realidade histórico-social e a sua projeção onírica de negação e substituição motiva vários excursos mais pontuais e com bastante interesse como as considerações sobre os gostos medievais quando o autor compara o que se come na Cocanha com o que se produzia e comia na época (sublinhando-se aqui que na Cocanha se verifica a ausência dos alimentos de base na época, como pão, sopa, queijo e vegetais, sendo estes alimentos pobres substituídos por comida de luxo, sobretudo ao alcance dos nobres: carne, peixe, vinhos e sobremesas). O tema da juventude eterna serve de pretexto para observações sobre os conceitos de jovem e de juventude (e sua independência relativamente à idade física) de acordo com o sistema de valores aristocrático, bem como sobre o significado da barba. A leitura do fabliau como possível descrição paródica dos banquetes das confrarias permite ao autor falar sobre estas estruturas de solidariedade no quadro de uma eventual crítica ao individualismo. A proposta de liberdade sexual veiculada pelo Fabliau de Cocagne remete para considerações sobre a sexualidade medieval e o seu controlo pela Igreja, aludindo-se, nomeadamente, à instituição do casamento nos séculos XI-XII e à sua inserção nos sacramentos, bem como a práticas, tabus, restrições e interditos impostos ao relacionamento sexual. Finalmente, a possibilidade de ler o texto como descrição idealizada e hiperbólica de uma taberna permite a aproximação com outros textos 
poéticos sobre tabernas e quem as frequenta e algumas considerações sobre esta realidade social, a sua popularidade enquanto pequenos locais festivos da predileção dos goliardos; o seu papel cultural no que se refere à difusão da cultura popular oral; e enquanto objetos de desejo onde se bebe e se come guloseimas, frequentemente também associados a bordéis.

Outras leituras serão por ventura um pouco mais ousadas ou mesmo discutíveis, apesar de sugestivas, como a que entende o fabliau como a descrição alegórica de uma trajetória pré-natal ou um sonho uterino; a articulação com o pensamento de Amaury de Bène (panteísmo); a interpretação do fabliau como metáfora de uma peregrinação a Jerusalém, identificando-se o narrador com Cristo, Cocanha com Jerusalém enquanto terra de abundância e a Fonte da Juventude com o Santo Sepulcro; ou ainda, por analogia com algumas canções de goliardos, a possibilidade de ler o texto como paródia à corte papal enquanto local de vida fácil, de festa contínua e onde os interditos impostos aos clérigos (sexuais, alimentares, económicos) são quebrados. O autor salvaguarda, no entanto, o facto das várias sugestões apresentadas constituírem hipóteses de leitura, deduzindo-se, por conseguinte, que a apresentação de múltiplas possibilidades interpretativas decorre de uma vontade de exaustividade.

Um assunto transversal que percorre o livro é a questão do autor do Fabliau de Cocagne. Por um lado, é dado adquirido a impossibilidade de indicar um texto original ou um autor concreto, ao que acresce o facto do texto se apresentar como um mosaico de ecos e de influências diversas, eruditas e populares, o que pode apontar para a existência de várias camadas redacionais e para a possibilidade de um percurso na memória coletiva de transmissão oral prévio à sua colocação por escrito. Pelo outro lado, Hilário Franco Júnior procura, em vários momentos do seu texto, identificar indícios que possam apontar para um ambiente de produção e um perfil de autor. Considera que o fabliau expressa as inquietações de diversos grupos sociais dos séculos XII e XIII, nomeadamente, dos camponeses (sonho insatisfeito de saciedade), da burguesia (concretização das suas aspirações materiais e sociais), da pequena e média aristocracia (fuga relativamente à evolução da sociedade e à sua decadência face à burguesia) e dos estudantes e intelectuais errantes (fuga ao dogmatismo e à hierarquização sociais e eclesiásticas). Deste leque, é valorizada a possibilidade de o autor ter sido alguém da pequena aristocracia laica, reconhecendo-se no entanto também 
o peso dos indícios que apontam para um elemento de uma confraria urbana. Este poeta anónimo poderá também ter sido um trouvère, um estudante ou, sobretudo, um goliardo. Estabelecidos os traços fundamentais que caracterizam Cocanha, o autor dedica os dois últimos capítulos do seu livro à fortuna medieval e pós-medieval do tema. O primeiro texto a retomar o assunto de que há conhecimento é o poema anglo-irlandês The Land of Cokaygne, de finais do século XIII ou inícios do XIV. Esta obra, claramente paródica, cujo autor terá sido um goliardo, adapta o tema a uma crítica feroz aos pecados de alguns monges (gula, luxúria, riqueza) enquadrável no contexto da rivalidade entre franciscanos e cistercienses, mais concretamente nas críticas que a ordem mais jovem e urbana dirigia contra o monaquismo tradicional. Várias diferenças entre os poemas francês e inglês são apontadas e esclarecidas com base em alterações do contexto histórico e social que viu nascer cada obra. O desenvolvimento da polifonia serve para justificar a presença de sons no poema inglês; a estética gótica explica a recorrência de referências à luminosidade e a valorização da luz, e o interesse por pedras preciosas e plantas remete para a sua relação com a farmacopeia e o interesse pelos elementos. Podemos, no entanto, perguntar-nos, até que ponto algumas das várias diferenças apontadas não serão possíveis nas duas épocas e nos dois locais, ou mesmo em qualquer época ou local, nomeadamente as que se referem ao modo de encarar a natureza ou a tendência mais paródica ou mais ideológica, traços estes que poderão radicar a sua origem em eventuais intenções, no modo de ser e de pensar, na maior ou menor capacidade de abstração ou ainda em simples idiossincrasias de cada autor independentemente de estes serem atualmente, para nós, anónimos.

Na sequência das mutações políticas, económicas, sociais, eclesiásticas e teológicas que se verificaram a partir do século XVI, o perfil sociológico do ideal da Cocanha altera-se. No entanto, a sua função de utopia de evasão permanece. Verifica-se o seu acantonar nas camadas mais pobres, enquanto representante do sonho de camponeses e do proletariado urbano, sendo olhada com desconfiança pela burguesia que a despreza como o ideal de preguiçosos e de vagabundos. Esta rejeição é reforçada pela sua associação às revoltas dos camponeses dos séculos XVI e XVII. Acresce ainda o facto da Cocanha divergir da corrente das utopias da época moderna, mais intelectuais e conservadoras, tanto nos temas, como nos valores. 
A apresentação do trajeto do tema da Cocanha a partir do período moderno passa pela consideração não só de versões literárias e iconográficas, mas também pela associação do nome a jogos e divertimentos que, de algum modo, remetem para a ideia geral ou para algum dos topoi que a compõem. São assim assinalados vários testemunhos que, em diversos locais, se inspiraram ou retomaram o tema da Cocanha, independentemente de o criticarem ou não. De entre as relativamente poucas versões francesas, é destacada a obra de Rabelais, tal como a obra de Milton é sublinhada para a Inglaterra. Na Alemanha, as críticas contra a Cocanha, enquanto terra de tontos e de preguiçosos, foram acerbas, o que também fornece indicadores sobre a extensão e importância do conhecimento do tema. Para a Holanda são destacadas as representações iconográficas na tradição do topos do mundo às avessas, especialmente por Bruegel, que também assume uma postura crítica. No que às versões italianas se refere, além de um conto de Boccaccio, é salientada a projeção da noção de Cocanha no Novo Mundo, associação esta que também se verifica na literatura espanhola.

Depois do desaparecimento progressivo de testemunhos sobre a Cocanha na Europa, o tema ressurge em meados do século XX num folheto de cordel do Nordeste brasileiro, uma zona muito pobre com condições precárias e onde a estrutura social guardou traços arcaicos. O texto "Viagem a São Saruê”, de Manuel Camilo dos Santos, apresenta evidentes diferenças culturais, mas, de acordo com o autor, a sua estrutura de base é idêntica. Sugere-se que o tema poderá ter sido transmitido pela tradição folclórica vinda da Europa que poderá ter convergido com a memória de tradições indígenas preexistentes (tribos primitivas sem hierarquias sociais, polígamas, ociosas e onde se verificavam fomes endémicas). Independentemente da sua fonte, não deixa de ser de grande interesse a existência deste eco tropical de um tema medieval europeu, mais um entre os vários que a zona nordestina nos preservou.

O livro é antecedido por uma interessante apresentação da autoria de Jacques Le Goff, que destaca os elementos fundamentais da obra: a fertilidade dos estudos sobre a interação entre países imaginários e sociedades históricas uma vez que o imaginário é uma representação tão real como as outras, se bem que de acordo com outra lógica; a importância do mundo utópico, fora do tempo histórico, para a compreensão da sociedade medieval, suas contradições, pulsões, aspirações, revoltas e audácias; e os quatro temas de fundo subjacentes a Cocanha, país sem lei, limites ou repressão. A 
bibliografia final é bastante completa apesar de se apresentar muito segmentada. As imagens que o livro integra são bastante eloquentes e ilustrativas do tema em análise e o índice remissivo é de grande utilidade.

Cocagne: Histoire d'un pays imaginaire, de Hilário Franco Júnior, é ainda um livro de leitura agradável, acessível a um público alargado e uma obra a reter pelo estudo global que desenvolve sobre um tema que ultrapassou o tempo e o local da sua origem e que, independentemente de ser produto de uma sociedade pré-industrial, não deixa de manter alguma atualidade enquanto reflexo de preocupações humanas e resposta a medos e anseios de caráter geral.

\section{COMO CITAR ESTE ARTIGO}

\section{Referência electrónica:}

DIAS, Isabel de Barros - “Recensão: FRANCO JÚNIOR, Hilário - Cocagne: Histoire d'un pays imaginaire. Préface de Jacques Le Goff. Paris: Les éditions Arkhê, 2013, 380 pp. [ISBN: 978-2-918682-2-19]”.

Medievalista [Em linha]. No 17 (Janeiro - Junho 2015). [Consultado 01.01.2015].

Disponível em http://www2.fcsh.unl.pt/iem/medievalista/MEDIEVALISTA17/dias1710.html ISSN 1646-740X.

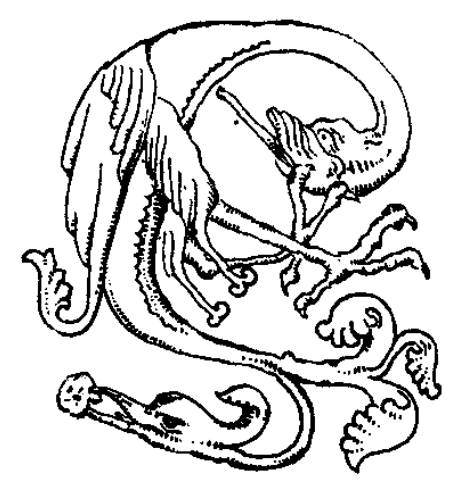

